University of South Carolina

Scholar Commons

1992

\title{
Mathematical Modeling of Cathodic Protection Using the Boundary Element Method with a Nonlinear Polarization Curve
}

\author{
J. F. Fan
}

Texas A \& M University - College Station

S. N. R Pakalapati

Texas A \& M University - College Station

T. V. Nguyen

Texas A \& M University - College Station

Ralph E. White

University of South Carolina - Columbia, white@cec.sc.edu

R. B. Griffin

Texas A \& M University - College Station

Follow this and additional works at: https://scholarcommons.sc.edu/eche_facpub

Part of the Chemical Engineering Commons

\section{Publication Info}

Journal of the Electrochemical Society, 1992, pages 1932-1936.

(c) The Electrochemical Society, Inc. 1992. All rights reserved. Except as provided under U.S. copyright law, this work may not be reproduced, resold, distributed, or modified without the express permission of The Electrochemical Society (ECS). The archival version of this work was published in the Journal of the Electrochemical Society.

http://www.electrochem.org/

DOI: $10.1149 / 1.2069524$

http://dx.doi.org/10.1149/1.2069524

This Article is brought to you by the Chemical Engineering, Department of at Scholar Commons. It has been accepted for inclusion in Faculty Publications by an authorized administrator of Scholar Commons. For more information, please contact digres@mailbox.sc.edu. 


\title{
Mathematical Modeling of Cathodic Protection Using the Boundary Element Method with a Nonlinear Polarization Curve
}

\author{
J.-F. Yan, ${ }^{*}$ S. N. R. Pakalapati, T. V. Nguyen, ${ }^{* *}$ and R. E. White** \\ Center for Electrochemical Engineering, Department of Chemical Engineering, Texas A\&M University, \\ College Station, Texas 77843-3122 \\ R. B. Griffin \\ Department of Mechanical Engineering, Texas A\&M University, College Station, Texas 77843-1292
}

\section{ABSTRACT}

The distributions of potential and current density around a cathodically protected pipeline in seawater were determined using the boundary element techniquc. A nonlinear polarization curve for a low carbon steel in artificial sea water was obtained from dc-potentiodynamic measurements and was fitted for use as the boundary condition on the pipe. "The program was used to evaluate cases in which one or two aluminum sacrificial anodes are used to protect a low carbon steel pipe in seawater. The results show that the number of anodes, the sizes of the anodes, and the distance between the anodes and the cathode are of importance for cathodic protection.

Cathodic protection (CP) is a technique to protect metallic structures against corrosion in an aqueous environment. As the protected structures become more complex, traditional methods for designing CP systems become less reliable. Consequently, mathematical methods are often used to calculate current and potential distributions on these complex structures.

At steady-state conditions, Laplace's equation

$$
\nabla^{2} \phi=0
$$

is the governing equation for the potential distribution in an electrolytc with uniform concentration profile and constant specific conductivity (1). Analytical solutions for Eq. [1] are limited to simple geometrical systems and linear boundary conditions. However, since most practical electrochemical systems consist of geometrical arrangements that are complex and include complicated, nonlinear boundary conditions, numerical methods are used typically to solve Eq. $\{1]$ and the associated boundary conditions to determine the desired potential and current density distributions. The numerical methods that are used mostly are the finite-difference mcthod (FDM) $(2,3)$ and the finiteelement method (FEM) (4-7).

These methods are satisfactory for systems with a finite domain, but are more difficult to apply to systems that include an unbounded domain, such as cathodic protection of pipelines and oflshore structures. In addition, corrosion engineers are mainly interested in the distributions of potential and current density along the structure/electrolyte interface in an electrochemical system and not in the electrolyte solution. For such problems, the boundary element method (BEM) seems the most appropriate. The BEM is a numerical technique that can be applied on unbounded systems and can be used to determine the potential and current density distributions along the clcctrodes without discretizing the electrolyte domain.

Previous workers have used the BEM to simulate cathodic protection systems (8-19), galvanic corrosion $(20,21)$, electroplating $(22)$, and electrochemical machining (23). A good comparison between the BEM and the FEM for compuler-aided design of cathodic protection systems is presented in Ref. (24). The available computer models for simulating potential and current distribution on cathodically protected structures were reviewed in Ref. (25).

The electrochemical reactions that occur on the cathode are described by a polarization curve, which is nonlinear in nature. The treatment of nonlinear polarization curves was done by using either linear interpolation (13-16) or iteration techniques (18-21). The types of polarization curves

* Electrochemical Society Student Member.

* Electrochemical Society Active Membor used in earlier work were the Tafel equation (18-20) or a second order polynomial equation (21). Unfortunately, neither of them includes the multiple electrochemical reactions and the mass transter of oxygen needed to describe the polarization curve of steel in scawater. A polarization curve obtaincd from dc-potentiodynamic measurements for a low carbon steel specimen in stagnant seawater is used as the boundary condition for the cathode in this paper. This polarization curve includes effects due to mass transfer and electrochemical kinetics.

\section{Method of Solution}

The boundary element rnethod.-As implied by its name, the BEM reduces Laplace's equation for the electrolyte domain to a surface equation by the application of Green's theorem $(26,27)$. The structure surface is discretized into a number of surface elements, and Laplace's equation is transformed to a linear system of equations

$$
\mathbf{G Q}=\mathbf{H} \Phi
$$

where $\mathbf{G}$ and $\mathbf{H}$ are the matrices of influence coefficients of the system geometry, and $\mathbf{Q}$ and $\Phi$ are the vectors of potential gradient and potential on the boundaries of the system, respectively. The detailed derivation of $\mathrm{Eq}$. [2] can be found elsewhere $(26,27)$.

The condition at infinity (20) can be incorporated into Eq. [2] by adding a charge conservation equation

$$
\int_{\tau} i d \tau=0
$$

This process yields an unknown potential at infinity, $\phi_{\text {... }}$, which is added to Eq. [2]. In an electrolyte with constant concentration and conductivity, the current density can be expressed by Ohm's law

$$
\begin{aligned}
i & =-k \frac{\partial \phi}{\partial n} \\
& =-k g
\end{aligned}
$$

where $k$ is the conductivity ol the clectrolyte and $n$ is the outward normal to the boundary $\tau$.

Three types of boundary conditions are commonly used in corrosion systems

$$
\begin{aligned}
& \phi=\phi^{\prime \prime} \\
& i=i^{\circ}
\end{aligned}
$$

and

$$
i=f(\phi)
$$

where $\phi^{\prime \prime}$ and $i^{\circ}$ are fixed values of potential and current density, respectively, on the boundaries of the systems. It is 


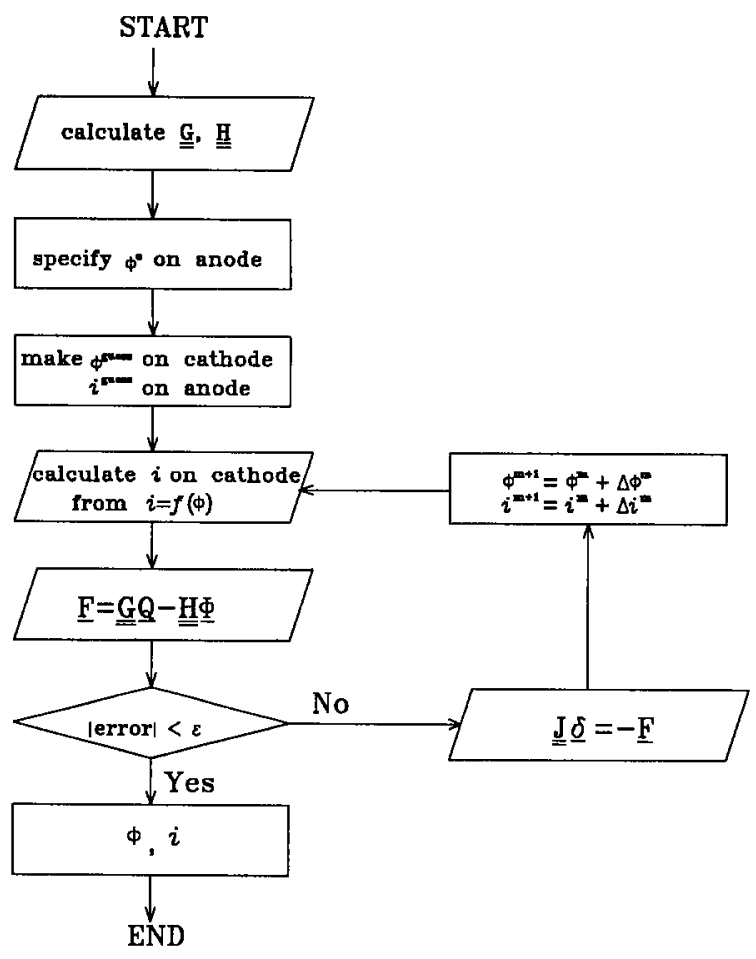

Fig. 1. Flow chart of the iteration algorithm in solving a cathodic protection problem using the BEM.

the nonlinear equation in Eq. [7] that makes the corrosion problems difficult to solve analytically.

The main task in using the BEM to model corrosion systems is to solve a system of equations, Eq. [2], associated with the boundary conditions, Eq. [5]-[7]. Figure 1 shows the flow chart using the BEM to solve a cathodic protection problem with Eq. [7] as a boundary condition on the cathode surface and Eq. [5] on the anode.

The influence coefficients in $\mathbf{G}$ and $\mathbf{H}$ in Eq. [2] are set values for a specific geometry. If ejther $\phi$ or $i$ is known, this linear system of equations can be solved directly by the Gaussian elimination method (28). However, if $\phi$ and $i$ are dependent on each other, as in Eq. [7], the Newton-Raphson method is used in the iteration procedure.

The solution procedure starts by calculating the influence coefficients in $\mathbf{G}$ and $\mathbf{H}$ matrices and by specifying the fixed potential of the sacrificial anodes, $\phi^{\prime \prime}$. Next, the iteration starts from guessing the initial values of potential $\phi^{\text {gurss }}$ on the cathode (in vector ( )) and $i^{\text {guss }}$ on the anode (in vector $\mathbf{Q}$ ) in Eq. [2]. The potential gradient on the electrode, $q$, is then calculated directly from Eq. [4] and [7]. An error vector $\mathbf{F}$ is defined as

$$
\mathbf{F}=\mathbf{G Q}-\mathbf{H} \boldsymbol{\Phi}
$$

Since in the $m$-th iteration all values are known, the error vector $\mathbf{F}$ can be determined by Eq. [8]. If all the absolute errors are not smaller than an allowable value, $\varepsilon$, the $m+$ 1 -th cstimate of $\phi$ on the cathode and $m+1$-th estimate of $i$ on the anode are calculated by the following equations

$$
\phi_{j}^{m+1}=\phi_{j}^{m}+\Delta \phi_{j}^{m} \quad j=\text { node on cathode }
$$

and

$$
i_{1}^{m+1}=i_{j}^{m}+\Delta i_{j}^{m} \quad j=\text { node on anode }
$$

where $\Delta \phi_{i}^{m}$ and $\Delta i_{j}^{m}$ are the increment of $\phi$ and $i$ in the $m+$ 1 -th iteration for node $j$. The $\Delta \phi_{j}^{n}$ and $\Delta i_{1}^{m}$ are determined by solving the following system of equations by the Gaussian climination method (28)

$$
\mathbf{J} \delta=-\mathbf{F}
$$

where $\mathbf{J}$ is the Jacobian of Eq. [8] and $\mathbf{F}$ is the error vector obtained from Eq. [8]. The iterature procedure is repeated until all errors in vector $\mathbf{F}$ become sufficiently small.
It is worth noting that the values used in the above computations are taken only from the boundaries of the structurc. Once Eq. [2] is solved, all the values of potential and current density on the boundaries are known.

Polarization curve.- The corrosion of steel structures in seawater is due to the oxidation reaction of iron

$$
\mathrm{Fe} \rightarrow \mathrm{Fe}^{2 t}+2 e
$$

oxygen reduction

$$
\mathrm{O}_{2}+2 \mathrm{H}_{2} \mathrm{O}+4 e^{-} \rightarrow 4 \mathrm{OH}^{-}
$$

and hydrogen evolution

$$
2 \mathrm{H}_{2} \mathrm{O}+2 e \rightarrow \mathrm{H}_{2}+2 \mathrm{OH}
$$

The theoretical current densities due to the individual reaction in Eq. [12]-[14] can be described by the following relations (29)

$$
\begin{aligned}
& i_{\mathrm{c}}=e^{s\left(p-\left(r^{2}\right) / s\right)} \\
& i_{r_{1},}=\left(\frac{1}{i_{\mathrm{I} .}}+\frac{1}{e^{\mathrm{s}\left(\phi-\phi^{*}\right) / / 6}}\right)^{1}
\end{aligned}
$$

and

$$
i_{\mathrm{c}_{2}}=e^{\mathrm{s}\left(\phi-0^{2}\right) / \mathrm{h}}
$$

where $i_{\mathrm{a}}, i_{\mathrm{c}_{1}}$, and $i_{\mathrm{c}_{2}}$ represent the current density generated by iron oxidation, oxygen reduction, and hydrogen evolution, respectively. In the above cquations, $i_{1}$ is the diffusion limiting current density, $b$ is the Tafel constant, and $\phi^{*}$ is a constant combining the open-circuit potential $\left(E^{\prime \prime}\right)$ and the exchange current density $\left(i_{1}\right)$ lor the activation polarization of an electron transfer reaction

$$
\phi^{*}=E^{\circ}-s b \ln i_{\text {n }}
$$

where $s=1$ lor anodic reactions and $s=-1$ for cathodic reactions. The total current density for the overall reaction can be obtained by summing the current densities due to the individual reaction as follows

$$
i=i_{\mathrm{a}}-i_{\mathrm{c}_{1}}-i_{\mathrm{r}}
$$

If $i$ at different values of $\phi$ can be obtained through experiments, the parameters in Eq. [15]-[17] could be acquired by the method of curve fitting.

\section{Experiment}

The low carbon steel specimens were machined as $6 \mathrm{~mm}$ in outer diameter by $9.5 \mathrm{~mm}$ long cylinders followed by progressive polishing with $\mathrm{SiC}$ paper. This was followed by mild polishing with abrasive paper, ultrasonic cleaning in a dilute acctone solution, and air drying. After attaching to the sample holder, the specimen was rinsed with deionized water and dried in air.

The clectrolyte was prepared by dissolving artificial seawater powder (Aquarium System, Ohio) in deionizcd water. The solution was then heated and stirred magnetically for $12 \mathrm{~h}$ and cooled down to the testing tempcrature.

The electrochemical experiments were performed in a standard corrosion cell. $\Lambda$ potentiostat (PARC Model 273) was used to control the potential by the aid of computer software (PARC, M342C) in a personal computer (IBM/ PS2, Model 30). The polarization curve was obtained by the application of dc-potentiodynamic technique. The scan rate used was $0.5 \mathrm{mV} / \mathrm{s}$.

\section{Results and Discussion}

A computer program (29) was used to determine the parameters $\phi^{*}$ and $b$ in each reaction, and $i_{\mathrm{T}}$, in oxygen reduction from the expcrimental data. The result for low carbon steel in artificial seawater is shown in Fig. 2 and has the following form

$$
i=e^{(\phi+1933911 / 2-4}-\left(\frac{1}{86.06}+e^{(1+1+5216) / 23.14}\right)^{-1}-e^{(141+707.57) / 55}
$$




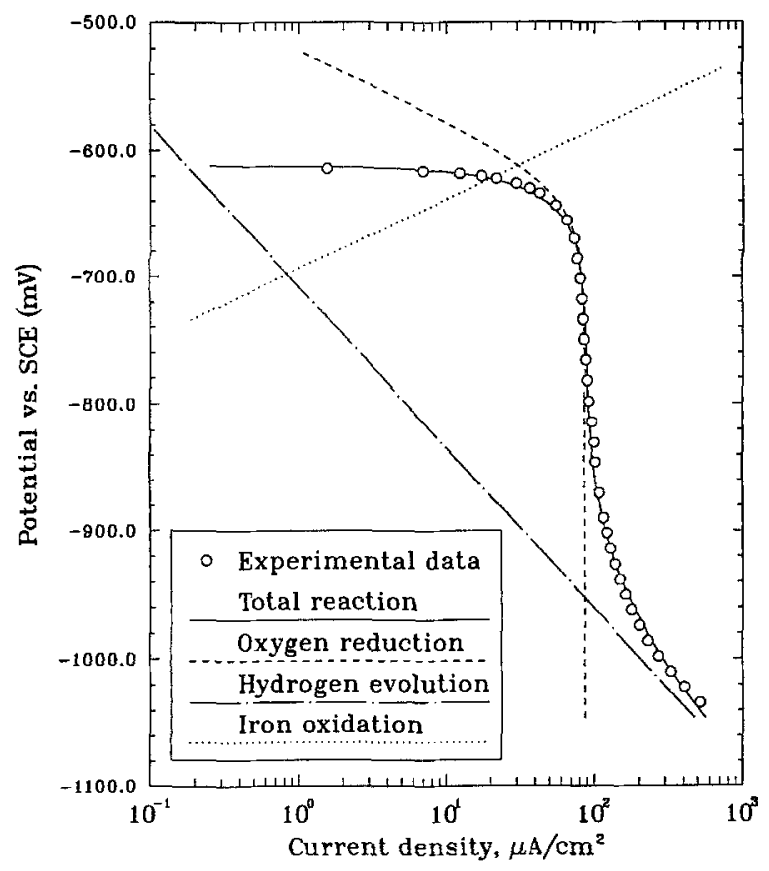

Fig. 2. Total current density and partial current densities due to the individual reaction during the polarization of a low carbon steel in artificial seawater.

with $\phi$ and $i$ having units of $\mathrm{mV}$ and $\mu \mathrm{A} / \mathrm{cm}^{2}$, respectively. The three terms on the right side of Eq. [20] are attributed to iron oxidation, oxygen reduction, and hydrogen evolution, respectively. Since the form of the polarization curve does not change for different ocean environments, the Jacobian (J) in Eq. [11] need not be altered. The information needed to calculate the polarization curve at different conditions are $\phi^{*}$ and $b$ for each reaction, and $i_{\llcorner}$for oxygen reduction.

The BEM discussed above is used to model a cathodic protection system consisting of a low carbon steel pipe (diameter $=60 \mathrm{~cm}$ ) in seawater (an infinite environment) having a conductivity of $4.79 \times 10^{-5} \mathrm{k}^{-1} \mathrm{~cm}^{-1}(30)$. As shown in Fig. 3, the aluminum alloy, with fixed potential of $-1055 \mathrm{mV}$ (vs. SCE), is used as the sacrificial anode to suppress iron dissolution and hence cathodically protect the pipe from corrosion. The geometry of the anode and its placement relative to the cathode are shown in Fig. 3 .

One anode.-Figure 4 shows the potential distribution around the pipe when a single anode as shown in Fig. 3 a at a distance of $10 \mathrm{~cm}$ is used. Due to the geometrical symmetry, only one-half, i.e., $0-180^{\circ}$, is represented in the figures. Steel is protected from corrosion if its potential with reference to $\mathrm{SCE}$ is below $-850 \mathrm{mV}$ (31). It can therefore be seen

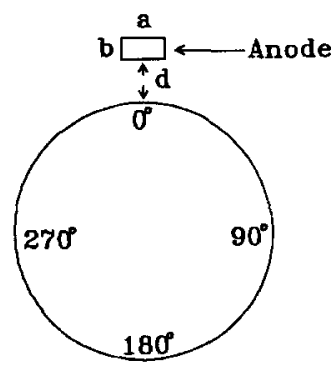

(a) One anode

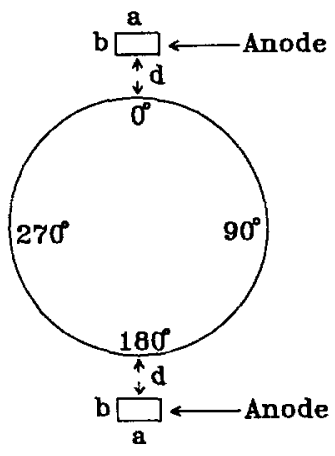

(b) Two anodes
Fig. 3. Schematic of the cathodic protection system of a low carbon steel pipe (diameter $=60 \mathrm{~cm}$ ) in seawater.

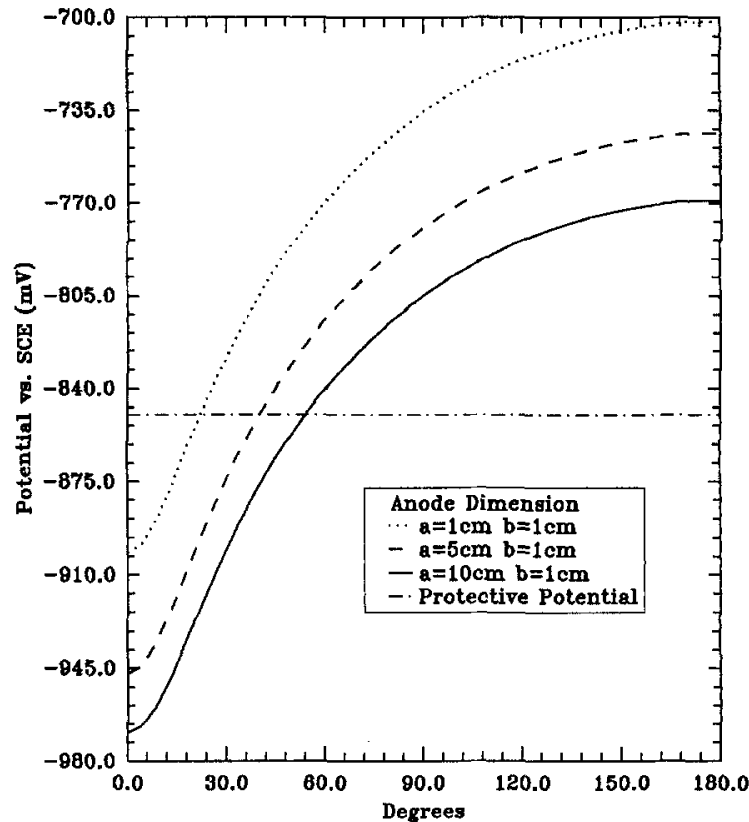

Fig. 4. Polential distribution around the pipe with one anode (refer to Fig. 3a) at a distance $d=10 \mathrm{~cm}$.

that the pipe surface is unprotected from corrosion except for regions close to the anode. Furthermore, if only one anode was used, it would have to be quite large to be able to bring the potential on the entire pipe surface to below the protective level.

Two anodes. - In order to avoid excessive anode material, two anodes may be used, placed at $0^{\circ}$ and $180^{\circ}$ as shown in Fig. 3b. The regions on the pipe surface most susceptible to corrosion (more positive potential) are those away from the anodes, i.e., around $90^{\circ}$ and $270^{\circ}$. A potential less than $-850 \mathrm{mV}$ (vs. SCE) at these regions would guarantee that the entire pipe surface is protected. However, the potential here is dependent on factors such as anode size and shape, its location with reference to the pipe, conductivity, etc. The variation of this potential (i.e., at $90^{\circ}$ and $270^{\circ}$ ) with distance of separation " $d$ " (Fig. 5) indicates a characteristic value at which the potentials at the two points is a minimum.

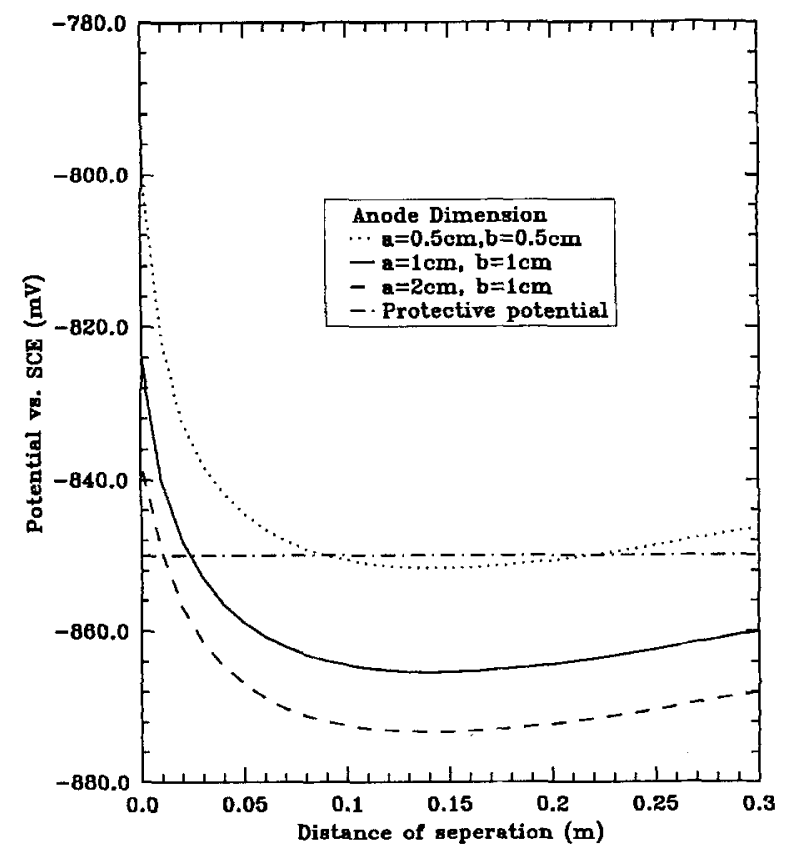

Fig. 5. Variation of potential (maximum) corresponding to 90 and 270 degrees on pipe (refer to Fig. 3b), with distance " $d$." 


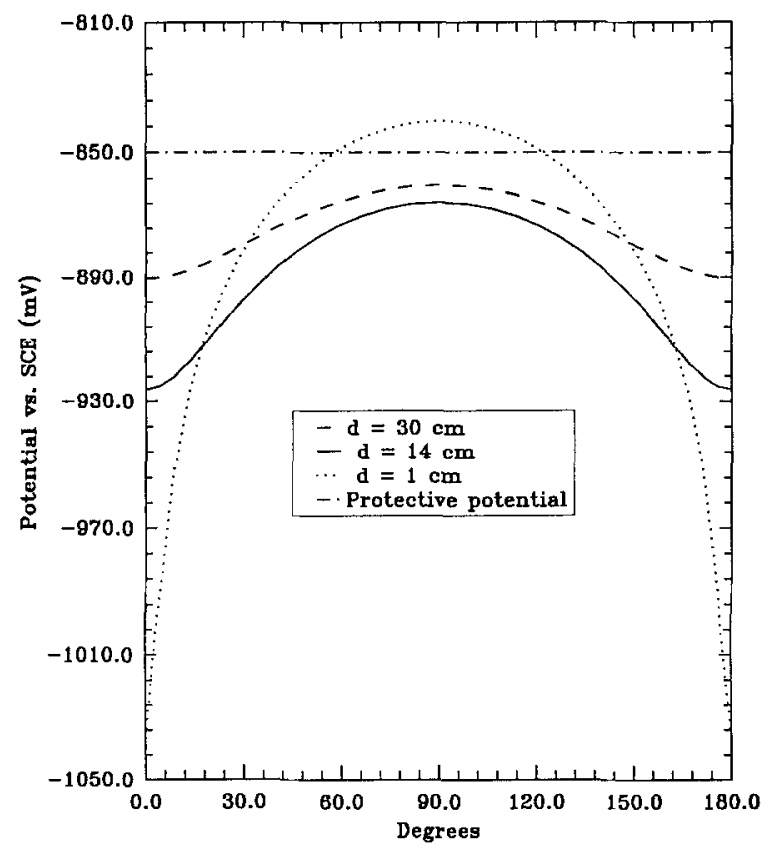

Fig. 6. Potential distribution around the pipe with two anodes (refer to Fig. $3 b)$, each of size $1 \mathrm{~cm} \times 1 \mathrm{~cm}(a=1 \mathrm{~cm}, b=1 \mathrm{~cm})$.

When the two anodes are placed $1 \mathrm{~cm}$ away from the pipe, the regions around $90^{\circ}$ and $270^{\circ}$ are above the protective potential of $-850 \mathrm{mV}$ (vs. SCE) (Fig. 6). The potential distributions around the pipe with anodes being placed at $14 \mathrm{~cm}$ and $30 \mathrm{~cm}$ are also shown in the figure. Figure 7 shows the corresponding current density distribution around the pipe.

Recently, more attention has been paid to the problems with time-dependent polarization curves $(17,32-34)$, especially in the ocean environment. The high $\mathrm{pH}$ value caused by the increase of $\mathrm{OH}^{-}$ion during cathodic protection is favorable for the formation of some inorganic layers, such as $\mathrm{CaCO}_{3}$ and $\mathrm{Mg}(\mathrm{OH})_{2}$ on the surface of protected structures. Such calcareous deposits have good resistance to oxygen diffusion, and the current density required for cathodic protection can be reduced. As a result, the polarization curve will change after a period of service time. Therefore, for the long-term design of corrosion systems, the

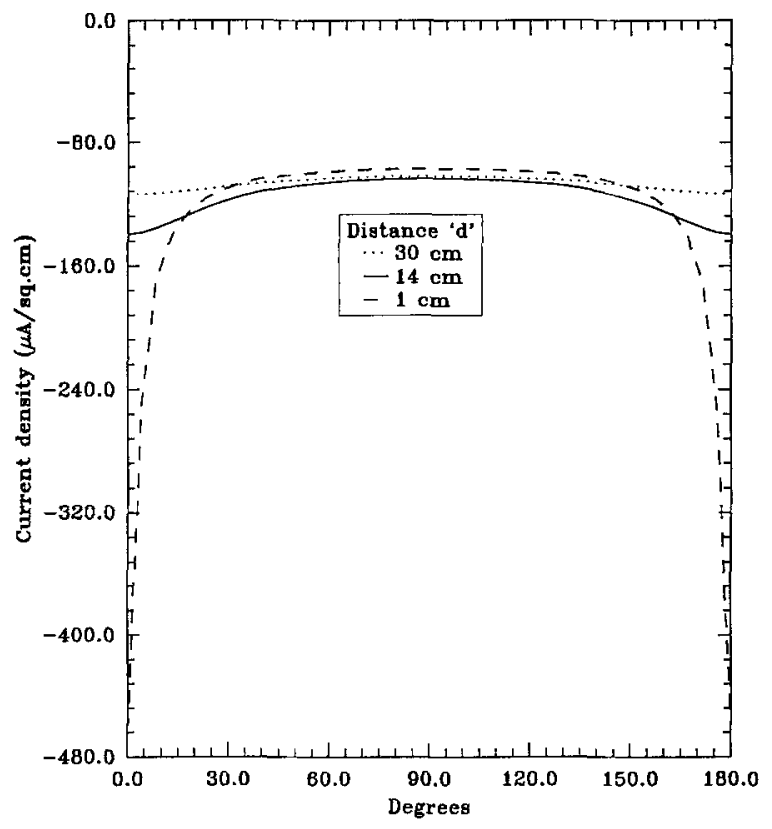

Fig. 7. Current density around the pipe with two anodes (refer to Fig. $3 \mathrm{~b})$, each of size $1 \mathrm{~cm} \times 1 \mathrm{~cm}(a=1 \mathrm{~cm}, b=1 \mathrm{~cm})$. time-dependent effects on the polarization curve have to be considered.

\section{Conclusions}

This BEM program developed for this work, which is available upon request from $R$. E. White, can be used to solve the two-dimensional Laplace's equation with nonlinear boundary conditions. A polarization curve, based on electrochemical principles, is obtained from experimental data and is used as the boundary conditions on the cathode surface. The results show that the number of anodes, the sizes of the anodes, and the distance between the anodes and the cathode are of importance for cathodic protection.

\section{Acknowledgments}

The authors acknowledge gratefully the financial support of this work by the Offshore Technology Research Center (OTRC) at Texas A\&M University. The authors also want to thank Dr. Devereux at the University of Connecticut for valuable discussions and useful suggestions in the modeling of the polarization curve.

Manuscript submitted Feb. 21, 1991; revised manuscript received March 6, 1992.

Texas A\&M University assisted in meeting the publication costs of this article.

\section{LIST OF SYMBOLS}

$b \quad$ Tafel constant, $\mathrm{mV}$

$E^{\circ} \quad$ open-circuit potential, $\mathrm{mV}$

$i$ current density, $\mu \mathrm{A} / \mathrm{cm}^{2}$

$i_{\text {a }} \quad$ current density due to iron oxidation, $\mu \mathrm{A} / \mathrm{cm}^{2}$

$i_{\mathrm{cl}} \quad$ current density due to oxygen reduction, $\mu \mathrm{A} / \mathrm{cm}^{2}$

$i_{\mathrm{c} 2}$ current density due to water reduction, $\mu \mathrm{A} / \mathrm{cm}^{2}$

$i_{\text {o }} \quad$ exchange current density, $\mu \mathrm{A} / \mathrm{cm}^{2}$

$i^{\text {guess }}$ guessed current density on the anode, $\mu \mathrm{A} / \mathrm{cm}^{2}$

$i_{\mathrm{L}} \quad$ limiting current density of oxygen reduction, $\mu \mathrm{A} / \mathrm{cm}^{2}$

$i_{j}^{n} \quad$ current density in $m$-th iteration associated with node $j, \mu \mathrm{A} / \mathrm{cm}^{2}$

$i_{j}^{m+1}$ current density in $m+1$-th iteration associated with node $j, \mu \mathrm{A} / \mathrm{cm}^{2}$

$\Delta i_{\mathrm{j}}^{m} \quad$ increment of current density in $m$-th iteration associated with node $j, \mu \mathrm{A} / \mathrm{cm}^{2}$

$k$ conductivity of seawater, $\mathrm{k} \Omega^{-1} \mathrm{~cm}^{-1}$

$m$ number of iteration

$n$ outward normal to the boundary $\tau, \mathrm{cm}$

$N$ number of nodes on boundary

$q$ potential gradient in normal. direction, $\mathrm{mV} / \mathrm{cm}$

$s \quad$ sign in Eq. [18]

Greek symbols

$\varepsilon \quad$ allowable error in iteration

$\tau \quad$ length of boundary, $\mathrm{cm}$

$\phi \quad$ potential, $\mathrm{mV}$

$\phi_{j}^{m} \quad$ potential in $m$-th iteration associated with node $j$ $\mathrm{mV}$

$\phi_{j}^{m+1}$ potential in $m+1$-th iteration associated with node $j$ $\mathrm{mV}$

$\Delta \phi_{i}^{m} \quad$ increment of potential in $m$-th iteration associated with node $j, \mathrm{mV}$

$\phi^{\circ} \quad$ set potential on the anode, $\mathrm{mV}$

$\phi^{*} \quad$ constant combining open-circuit potential and exchange current density, $\mathrm{mV}$

$\phi_{\infty}$ potential at infinity, $\mathrm{mV}$

$\phi^{\text {suess }}$ guessed potential on the cathode, $\mathrm{mV}$

Vectors and matrices

G matrix of influence coefficients of system geometry

H matrix of influence coefficients of system geometry

J Jacobian of the system of equations

Q vector of $q,\left[q_{1}, q_{2}, \ldots, q_{N}\right]^{\mathrm{T}}$

$\mathbf{F}$ vector of error in iteration procedure

$\delta \quad$ increment vector in iteration procedure

$\Phi$ vector of $\phi,\left[\phi_{1}, \phi_{2}, \ldots, \phi_{\mathrm{N}}, \phi_{\mathrm{os}}\right]^{\mathrm{T}}$

\section{REFERENCES}

1. J. S. Newman, "Electrochemical Systems," PrenticeHall, Inc., Englewood Cliffs, NJ (1973).

2. P. Doig and P. E. J. Flewitt, This Journal, 126, 2057 (1979).

3. R. Strommen and A. Rodland, Materials Performance, 20, 15 (1981). 
4. R. S. Munn, Corrosion, 38, 29 (1982).

5. J. W. Fu, ibid., 38, 295 (1982).

6. R. Kasper and M. G. April, ibid., 39, 181 (1983)

7. E. A. Decarlo, Material Performance, 22, 38 (1983).

8. J. W. Fu, Corrosion, 38, 9 (1982).

9. D. J. Danson and M. A. Warne, CORROSION/83, Paper No. 211, National Association of Corrosion Engineers, Houston, TX (1983).

10. S. Aoki, K. Kishimoto, and M. Miyasaka, Corrosion, 44, 926 (1988).

11. R. Stommen, W. Kein, J. Finnegan, and P. Mehdizadeh, Materials Performance, 26, 23 (1987).

12. P. Cicognani, F. Gasparoni, B. Mazza, and T. Pastore, This Journal, 137, 1689 (1990).

13. D. J. Danson, C. A. Brebbia, and R. A. Adey, in "Finite Element Systems," C. A. Brebbia, Editor, pp. 81-99, Springer-Verlag, Berlin (1987).

14. W. J. Mansur, L. C. Wrobel, J. C. F. Tells, J. P. S Azevedo, and J. A. F. Santiago, in "Boundary Element Techniques," C. A. Brcbbia and W. S. Veturini, Editors, pp. 139-159, Springer-Verlag, Berlin (1987)

15. J. C. F. Telles, L. C. Wrobel, W. J. Mansur, and J. P. S. Azevedo, in "Boundary Elements VII," C. A. Brebbia and G. Maier, Editors, pp. 1-73 to 1-83. SpringerVerlag, Bcrlin (1985)

16. R. A. Adey, C. A. Brebbia, and S. M. Niku, in "Topics in Boundary Element Research," Vol. 7 Electrical Engineering Applications, C. A. Brebbia, Editor, pp. 3464, Springer-Verlag, Berlin (1990.

17. P. O. Gartland and R. Johnsen, CORROSION/85, Paper No. 319, National Association of Corrosion Engineers, Houston, TX (1985).

18. N. G. Zamani and J. S. Porter, in "Boundary Element Techniques," C. A. Brebbia and W. S. Veturini, Editors, pp. 123-137, Springer-Verlag, Berlin (1987).

19. N. G. Zamani, Appl. Math. Computation, 26, 119 (1988).

20. N. G. Zamani, J. M. Chuang, and J. F. Porter, Int. J. Numerical Methods in Eng., 24, 605 (1987).
21. S. Aoki and K. Kishimoto, in "Topics in Boundary Element Research," Vol. 7 Electrical Engineering Applications, C. A. Brebbia, Editor, pp. 65-86, SpringerVerlag, Bcrlin (1990)

22. L. J. Gray, G. E. Giles, and J. B. Bullock, in "Boundary Element Techniques," C. A. Brebbia and W. S. Veturini, Edaitors, pp. 161-173, Springer-Verlag, Berlin (1987)

23. J. Deconinck, G. Maggetto, and J. Vereecken, This Journal, 132, 2960 (1985).

24. R. A. Adey and S. M. Niku, in BETECH 85, C. A. Brebbia and B. J. Noye, Editors, pp. 269-298, SpringerVerlag, Berlin (1985)

25. K. Nisancioglu, "Modelling for Cathodic Protection," Proceedings of 2nd Industrial Conference on $\mathrm{Ca}$ thodic Protection Theory and Practice, European Federation of Corrosion Event 157, Stratford-uponAvon, June 1989

26. C. A. Brebbia, "The Boundary Element Method for Engineers," Pentech Press, London (1978).

27. C. A. Brebbia, J. C. F. Telles, and C. C. Wrobel "Boundary Element Techniques," Springer-Verlag, Berlin (1984).

28. R. Carnahan, H. A. Luther, and J. O. Wilkes, "Applied Numerical Methods," John-Wiley \& Sons, Inc., New York (1969).

29. K. S. Yeum and O. F. Devercux, Corrosion, 45, 478 (1989).

30. M. Whitfield and D. Jagner, "Marine Electrochemistry," John-Wiley \& Sons, Inc., New York (1981).

31. W. H. Hartt, W. Wang, and T. Y. Chen, CORROSION/ 89, Paper 576, National Association of Corrosion Engineers, Houston, TX (1989).

32. K. Nisancioglu and P. O. Gartland, Inst. Chem. Eng Symp. Ser. No. 12, p. 211, The Institution of Chemical Engineers, Rugby, UK (1989).

33. K. Nísancioglu, Corrosion, 43, 100 (1987).

34. K. Nisancioglu, P. O. Gartland, T. Dahl, and E. Sander, ibid., 43, 710 (1987).

\title{
Point of Zero Net Adsorbed Charge of Gallium Arsenide
}

\author{
Roland Schlesinger and Peter Johannes Janietz \\ Institute of Physical and Theoretical Chemistry, Humboldt University, Berlin O-1080, Germany
}

\section{ABSTRACT}

For powdered GaAs the point of zero net charge at the inner Helmholtz plane has been determined to be about 5.9. To account for the discrepancy between this experimental value and a theoretical onc based upon a relation between the electron affinity and the flatband potential of GaAs, interface states and dipole contributions to the potential difference across the semiconductor/electrolyte interface have been invoked. By reinvestigating the dependence of the liatband potential on redox couples added to the solution, convincing interface state densities have been found, which indeed bring the theory in accordance with experiment. The gap states have been ascribed mainly to the atomic disorder at the oxidecovered semiconductor surface.

Except for Ref. (1), it is generally accepted (2-6) that the flatband potentials $\left(V_{\mathrm{FB}}\right)$ for n-GaAs electrodes show a normal Nernstian response with respect to $\mathrm{pH}$ variation. This behavior has been attributed to a protonation-deprotonation equilibrium at a hydroxide layer on the semiconductor surface or to specific adsorption of $\mathrm{H}^{+}$and $\mathrm{OH}$ ions at oxidic surface sites (7). This implies that a unique $\mathrm{pH}$ value, called the point of zero zeta potential (PZZP) by Butler and Ginley (8), exists where the net charge located at the inner Helmholtz plane is zcro.

Though the PZZP of numerous oxidic and nonoxidic semiconductors, including $\mathrm{GaP}(9)$, have been evaluated in the past, up to now no experimental value for GaAs has been reported.

Horowitz et al. (5) using an equation derived by Butler and Ginley (8), which relates the electron affinity $(E A)$ of the scmiconductor to $V_{\mathrm{FB}}$ at $\mathrm{PZZP}$, attempted to determine the PZZP for GaAs theoretically. Unfortunately, these authors did not consider that at PZZP a potential drop across the oxidic surface layer and the Helmholtz layer duc to the existence of interface dipoles and of charged interface states may occur. In the present authors' opinion, it is at the least not justified to neglect the excess charge left in electronic surface states at $V_{\mathrm{FB}}$, which must be compensated by an ionic counter charge in the electrolyte.

In this paper we report the experimental detcrmination of the point of zero net charge at the inner Helmholtz plane (PZC) for GaAs and demonstrate the correct use of the Butler-Ginley equation in relating $V_{\mathrm{l}: \mathrm{B}}$ at $\mathrm{PZC}$ to $\mathrm{EA}$. In order to deduce the interface state density affecting this relation, the dependence of $V_{\mathrm{FB}}$ on redox couples added to the electrolyte has been reinvestigated.

\section{Experimental}

(100)-oriented n-GaAs single-crystal wafers doped with Te $\left(6 \times 10^{17} \mathrm{~cm}^{-3}\right)$ were used throughout this study. Before use in electrochemical investigations, the samples were subjected to the following treatments. After a degreasing procedure the chemomechanically polished front faces were treated in an ultrasonic $1: 1 \mathrm{NH}_{3}-\mathrm{HI}_{2} \mathrm{O}$ bath for remov- 